\title{
Building Negotiated Agreement: The Emergence of Community-Based Tourism in Floreana (Galápagos Islands)
}

\author{
Esteban Ruiz-Ballesteros and Eduardo S. Brondizio
}

\begin{abstract}
Community Based Tourism (CBT) is a polysemic term referring to local involvement in the planning, development, and management of tourism. While there is no direct correspondence between CBT and positive economic and conservation outcomes, CBT is a frame widely used to reconcile tourism development with social-environmental goals. Building upon the case of the island community of Floreana, within the Galápagos National Park (GNP) in Ecuador (where tourism activities have introduced major environmental problems), this paper analyzes the emergence of CBT as part of multi-level processes of institutional crafting. Efforts to develop a new model of tourism management in Galápagos, strongly shaped by a particular community, offer a quasi-experimental case of rule-crafting aimed at developing a participatory, multi-level governance system. Our approach integrates ethnographic fieldwork and discourse analysis with the Institutional Analysis and Development (IAD) framework to identify key elements associated with the process of implementing CBT. We discuss three points of broader relevance: the inter-dependence of regional and local levels, the importance of considering worldviews and the intended outcomes envisioned by different actors, and the importance of coherence in rule-crafting (across levels and types of rules) defining control and regulation of $\mathrm{CBT}$ development and of tourism operations.
\end{abstract}

Key words: commons, community based tourism, multi-level governance, institutional analysis

\section{Introduction}

$\longrightarrow$ ommunity based tourism (CBT) refers to local involvement in the planning, development, and management of tourism. It assumes that this local participation has positive effects on both socioeconomic development and conservation. These outcomes, however, are subject to extensive academic debate (Hiwasaki 2006; Kruger 2005; Li 2006; Okazaki 2008; Roberts and Tribe 2008; Ruiz-Ballesteros 2011; Ruiz-Ballesteros and HernándezRamírez 2010; Stem et al. 2003; Stronza 2010; Tao and Wall

This article is a partial result of the research projects "Anthropology of Conservation in the Galápagos" (Charles Darwin Foundation and the Pablo de Olavide University); and "Retóricas de la naturaleza y Turismo de Base Local: Estrategias de sostenibilidad" (Ministry of Economy, CSO2012-33044). Pedro Cantero and Javier Andrada participated in the fieldwork in Floreana. The combined work of the authors of this article was carried out during Esteban Ruiz-Ballesteros position as visiting scholar at the Anthropological Center for Training and Research on Global Environmental Change at Indiana UniversityBloomington financed by the Spanish Ministry of Education in 2012. Brondizio also thanks the Institut d'Etudes Avances-Paris for its support during the revision and resubmission of this article. The authors thank Gustavo Garcia for his careful editing and constructive comments on the initial manuscript.
2009; Theodori 2005; Tosun and Timothy 2003; Wunder 2000). CBT is a polysemic term representing various forms of tourism operating in different contexts; thus, scholars and practitioners agree that there is no mechanical correspondence between CBT and economic development and conservation. On the other hand, CBT has offered a framework strongly supported by international organizations and NGOs (WTO 2006; World Wide Fund for Nature 2001), governments, international development agencies, and indigenous peoples. It has also become a strategy for implementing tourism and sustainable management particularly within and around protected and indigenous areas.

The goal of this paper is to discuss and analyze the emergence of CBT as part of multi-level processes of institutional crafting. We examine the design of a CBT proposal involving the island community of Floreana, located within the Galápagos National Park (GNP) in Ecuador. In particular, we discuss the process of rule-crafting within and between levels of governance guiding tourism development. We examine the role of different stakeholders, their worldviews and priorities regarding intended outcomes, and how these differences influence the crafting and change of different types of rules, that is, boundary, position, scope, and choice rules (Ostrom 1990), required for the transition towards CBT. Our approach integrates ethnographic fieldwork and discourse analysis with 
the Institutional Analysis and Development (IAD) framework (Ostrom 1990, 2011).

\section{Theoretical and Methodological Framework}

Tourism is a type of activity that draws upon (sometimes not exclusively) the various resources available in a socioecological system. Frequently, its development entails a new, specific, and complementary use of pre-existing resources or even the emergence of new resources. The goods and services used through tourism activities are of a highly heterogeneous nature encompassing biophysical and cultural elements in their tangible and intangible dimensions (e.g., wildlife, landscape, forest, sea, cultural practices, architecture, arts, public infrastructure, etc.). Moreover, tourism-related resources are subject to different types of property regimes: open access, communal, public, and private, while combining different types of goods (i.e., private, public, or toll), depending on the scale at which one considers them. Although tourism involves a complex and comprehensive use of resources within a socioecological system, it cannot be conceptualized in itself as a good nor as a common pool resource (CPR), but instead as a rationale for using them. There is a growing literature proposing the analysis of tourism from the perspective of common pool resources (Briassoulis 2002; Healy 2006; Holden 2005; Moore and Rodger 2010; Stronza 2010), as the nature of the most important goods and services used in tourism make this perspective relevant.

Community-based tourism in protected areas entails a particular way of using resources at the local level. These goods and services are subject to different levels of exclusion and subtraction and overlapping types of property regimes in their production or consumption (McGinnis 2011a; Ostrom 1990). It seems worthwhile, albeit challenging, to analyze this type of tourism from a CPR's perspective for the following reasons: (1) following the criteria of subtractability and high costs of exclusion, most of the main resources used in community-based tourism activities have the character of commons pool resources (e.g., landscape, forest, sea, cultural practices); (2) tourism management entails community-based normative institutions; and (3) the emergence and/or expansion of community-based tourism, as it involves new forms of use of multiple resources, adds institutional and economic complexity to CPR management (Stronza 2010). Thus, analyzing community-based tourism through the lens of CPRs may help us to capture the complexity of tourist activities within a socioecological system more comprehensively than other perspectives.

A good deal of literature indicates the centrality of local governance systems in regulating the use and management of CPRs (Acheson 2006; Ostrom 1990, 2005). Initiatives to change tourism activities from business-as-usual to CBT usually aim at improving the participation of local communities in the process. As with other CPR governance initiatives, however, tourism involves local and regional actors, state agencies, NGOs, and a variety of private interests, thus requiring consideration of multiple levels of collective action and governance (see Berkes 2002; Brondizio, Ostrom, and Young 2009; Taylor and Cheng 2012). Consequently, transforming tourism initiatives into community-based projects is not a single-actor endeavor. Only coordinated action across levels allows for substantial transformation in tourism practices.

The Galápagos Islands have a long and controversial history of tourism management, often serving as an example of the negative social and environmental impacts of conventional tourism. Efforts to develop a new model of tourism management, strongly shaped by a particular community, offer a quasi-experimental case of rule-crafting aimed at developing a participatory, multi-level governance system. As in all inhabited protected areas, there is a fine line between the worldview and politics of conservation and economic development aimed at improving the well-being of local communities (West, Igoe, and Brockington 2006). Tourism, CBT in particular, is often assumed to offer a potential path towards balancing these goals, notwithstanding the complex challenges involved in the process. It also poses a challenge to analytical strategies aimed at understanding the process and outcomes of tourism development.

Through a case study approach (Poteete, Jansen, and Ostrom 2010; Yin 2009) linking the local (Floreana Island) and regional (Galápagos archipelago) levels, we seek to identify key elements associated with the process of transformation from business-as-usual to CBT in the region. Through this case study, we discuss the crafting of a new tourism governance system as a process resulting from the dynamics of collective action within and across local and regional levels. We use the IAD framework (Ostrom 2011) to analyze such action at the regional and local levels, as well as the linkages between them. The strength of this framework lies in its holistic approach to the analysis of collective action; that is, its consideration that individuals and groups operate within a nexus of biophysical, political, cultural, and economic factors defined by various sets of rules and constraints (Ostrom, Gardner, and Walker 1994). In combination with extensive ethnographic fieldwork and discourse analysis, the IAD framework helps us to define relationships between participants, context (within and across levels), existing and proposed rules associated with changes in tourism, and the alignment (or lack thereof) of different types of rules (Ostrom, Gardner, and Walker 1994).

We find these analytical tools particularly useful to examine changes in various categories of rules and the social processes involved in crafting them as social groups compete and cooperate to transform a multifaceted activity such as tourism. Organizing these social dynamics as "action situations" provides us with analytical resources "that can be utilized to describe, analyze, predict, and explain behavior within institutional arrangements" (Ostrom 2011:11). Within these action situations, we attend to participants as endowed with resources, perceptions, knowledge, alliances, and worldviews that are central to understanding differences in intended outcomes and the formulation of rules to achieve 
them. Following Ostrom (2011), we recognize that IAD also has limitations as an analytical tool. Nonetheless, it provides a comprehensive and flexible structure that allows us to represent the system in its multi-level complexity and to delineate different categories of rules involved in the crafting of new institutions.

IAD and its subsidiary theoretical stance on bounded rationality (Poteete, Janssen, and Ostrom 2010) offer a systematic analytical framework to examine institutional crafting as a process. Following other scholars (Acheson 2011; Sick 2008; Taylor and Cheng 2012; Wagner and Talakai 2007), we maintain that such analyses must be grounded in solid ethnographic evidence. Through ethnography, we can approach the "attributes of the community" as set out in the IAD framework, focusing on such central issues as trust, reciprocity, common understanding, and worldviews and their effects on the collective action process (McGinnis 2011a). An anthropological approach based on the analysis of discourses and practices brings to the fore participants' perceptions as they play out within particular contexts and social situations (Natcher, Davis, and Hickey 2005; Neves-Graça 2004). Thus, ethnographic work is essential to understanding the negotiations, power relations, and worldviews of participants. This complementarity of approaches allows for a fine-grained examination of action situations within and across the levels (Berkes 2002; Ostrom 1990) involved in the transformation of tourism governance, both in Galápagos and elsewhere.

Our analysis is based on seven months of ethnographic research in Galápagos and the island of Floreana carried out by three investigators from 2009 to 2011. The research team dedicated significant time to participant observation in meetings and deliberations pertaining to the development and consolidation of a CBT model for Floreana. At the level of Floreana, the team carried out comprehensive ethnographic research including sociodemographic, institutional, and economic assessments at household and community-levels, as well as in-depth interviews regarding local perspectives about quality of life, tourism, development, and environment. At a regional level, interviews and participant observation focused on the organizational structure and narratives of NGOs and the management office of the GNP. Our inquiries sought to elicit their views on implementing a new model of tourism throughout the archipelago and in Floreana in particular. It also afforded a systematic analysis of institutional crafting as shaped by social and power dynamics and the worldview of participants within and across levels of negotiations. With our ethnographic work across these levels, we also hope to establish a foundation from which to follow the process into the future.

\section{Study Context: Galápagos and Floreana}

Few places in the world have the significance of Galápagos as natural space. The islands' geo-environmental conditions and their late settlement by humans have transformed them in a "paradise" of endemic flora and fauna and a labora- tory for the study of biological evolution. With its declaration as a National Park (1959) and a World Heritage Site (1979), the Galápagos acquired a privileged position within nature tourism on a global scale. Since then, the natural, scientific, and touristic significance of these islands have constituted an inextricable whole (Grenier 2007).

The evolution of this socioecological system is marked by two main factors. One is the increase in the permanent human population from only 4,000 inhabitants in 1974 to 25,124 in 2010 (INEC 2011) due to marked in-migration. The other is the increasing presence of introduced (non-native) species; despite eradication campaigns and the fact that 97 percent of the territory is under strict environmental protection, this has resulted in a notable alteration of the islands' ecology (Gardener, Atkinson, and Rentería 2010; Watson et al. 2010). The factors driving these changes include state subsidies, abandonment of agriculture, institutional and political instability, and weak governance and leadership, but above all tourism (Gonzalez et al. 2008). The tourist development of the Galápagos seems unstoppable, despite attempts to control it. The number of visitors increased from 11,795 in 1979 to 185,028 in 2011 (GNP 2012). This reflects an unprecedented "opening up" of an archipelago which was practically isolated from the exterior until the 1970s (Grenier 2007).

Galápagos exemplifies the dilemmas of managing tourism in CPR contexts. Despite multiple laws and regulations designed to control it (e.g., defining site visits, caps on the number of visitors), tourism continues to grow at a marked pace. The first modality of cruise ship tourism controlled by large corporations has been complemented by a second modality of "daily tours" using small boats, which centers on the populated areas and encourages as CBT does increased local involvement in the benefits from the tourism. Nevertheless, this second type of tourism is becoming increasingly problematic because of the inherent difficulty of controlling and regulating it. Therefore, even though this modality assumes that benefits will flow to local populations, it also carries potential negative environmental (and social) impacts. Moreover, it implies moving a step closer to the abandonment of other activities, especially agriculture and ranching, which are highly relevant for the socioecological sustainability of the archipelago (Andrada, Cantero, and Ruiz-Ballesteros 2010).

Each island in the Galápagos exhibits different conditions and dynamics with respect to the development of tourism. These island-level particularities must be taken into account when examining tourism in the park as a whole (Andrada, Cantero, and Ruiz-Ballesteros 2010). The delayed incorporation of Floreana Island into the principal tourist flows of GNP and its relative isolation until recent years resulted in low population levels, and a focus on a quasi-subsistence economy to locals are very attached. This economy has been slowly modified as a result of two parallel processes: on one hand, the increasing presence of the State as an agent of administration and conservation; and on the other, the development of tourism. 


\section{Figure 1. Galapagos and Floreana}

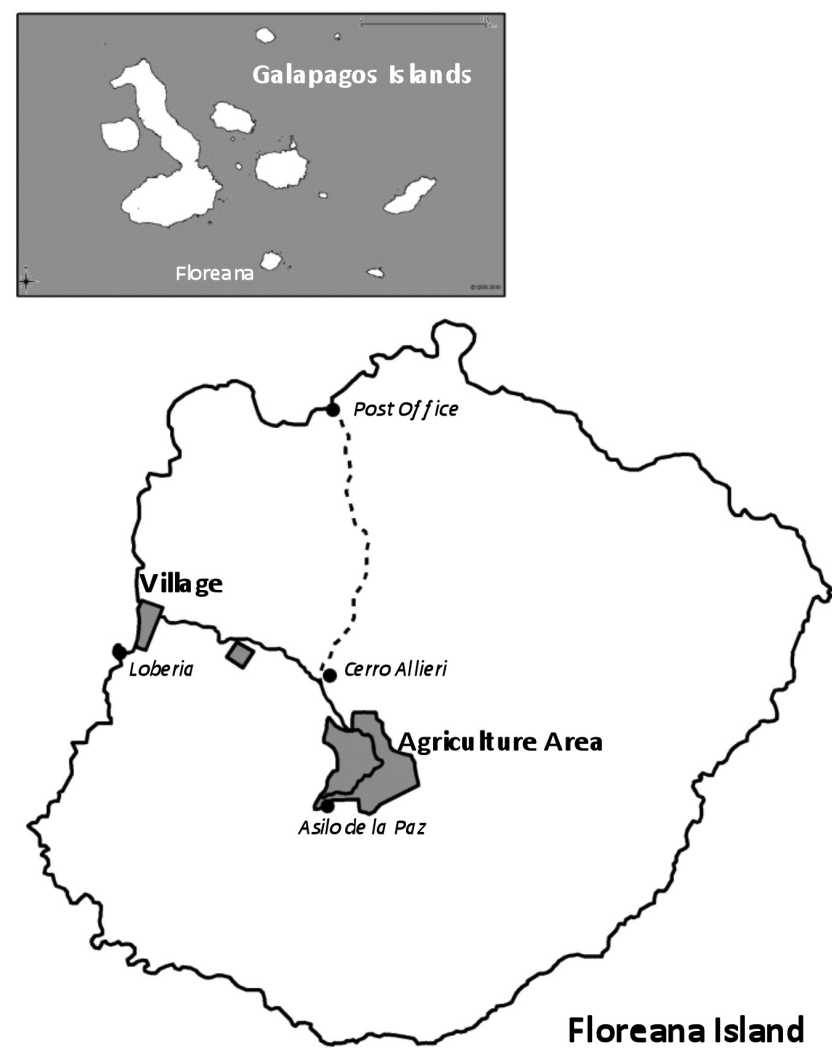

With a land area of $173 \mathrm{~km}^{2}$, Floreana has the smallest population in the Galápagos archipelago (just 164 inhabitants in 2011). Ninety-eight percent of the island's territory is theoretically segregated from any human activity or settlement as part of the GNP, and the rest is divided between the village settlement on the coast (39 hectares) and agricultural land in the central part of the island (271 hectares) (see Figure 1). The main property regime in the island is public, extended over the entire area of the GNP and the urban infrastructure; housing and the agricultural zones are under private property. The island was officially occupied in 1832, but afterwards it suffered several periods of abandonment. Since the 1930s, the island has remained populated, but half of the families that live there today arrived less than 30 years ago. The island receives cruise ships on its uninhabited northwest coast (Post Office), and consequently this modality of tourism provides no benefit to the local population.

Since 2008, the development of the "daily tour" form of tourism has drastically changed the impact of tourism on the island. In 2011, there were an estimated 23,000 visitors. These tourists come from the island of Santa Cruz and stay only an average of five hours in Floreana. They visit the higher elevations points of the island, where there are remains of the first human occupation of the archipelago (Asilo de la Paz) and eat lunch in one of the town's restaurants. Our data reveal that the cost of the trip is approximately $\$ 70$ per person of which only 15 percent stays in Floreana while the rest goes to the tour operators and the boats' owners from Santa Cruz. An average of 64 tourists visit the island daily, but during the high season, this number is much greater and surpasses the local population. While limited in number, these visits have had an impact on the island unknown only four years ago. Floreana's residents provide transportation and food services to tourists. The few that stay overnight (according to our data, less than 20 percent) represent the atypical island visitor but have nonetheless had some impact on the local economy.

To understand how the island's economy operates, we took as a reference its 31 households. Our data show that in 2011, 27 of these households (91 percent) produced food for home consumption, dedicating only 26.1 percent of their production for sale (INEC 2009). In addition, 15 households (almost 50 percent) received income from tourism, 19 (63.1 percent) from employment in government or NGOs, and 11 in construction projects. This can be described as a diversified economic system combining market-based employment and a logic of self-consumption. This balance substantially influences the socioecological reality of the island, as well as its perspectives for the future. Although based in a regime of private property, agro-livestock activities are highly marked by norms of reciprocity and mutual help, particularly through collective work and owners' willingness to share land (free of charge) with non-owners. It could be expected that tourism development would hasten the abandonment of these quasisubsistence farming and livestock activities, as has occurred in other islands in the Galápagos. For now, however, the trend in Floreana has been in the opposite direction. New land under cultivation, the sale of land, and the creation of a local farmers' association underscore this trend.

Floreana's inhabitants are fully cognizant of what has taken place in other islands with the development of commercial fishing first, and tourism later: the rapid disappearance of norms of reciprocity and community solidarity, an increase in population, and an irreversible process in which tourism imposes itself on the rhythm of life. All of this makes Floreanos zealous in defending their way of life. This does not, however, imply that they are uninterested in improving their consumptive capacity, and above all their connectivity to the rest of the archipelago and the continent. As a result, tourism is the object of collective reflection in Floreana, as confirmed during our extended fieldwork.

\section{Towards a New Tourism: A CPR Governance System in Floreana}

For the organizations working on conservation in the Galápagos, Floreana offers the final opportunity to develop a model of sustainable tourism. In 2010, the GNP, NGOs, and regional and national authorities reflected on the suitability of modifying the tourist model in the Galápagos. A number of meetings, seminars, and encounters took place, leading to the establishment of a model of ecotourism for the archipelago. 
Regional and national tourism entrepreneurs, who until now were isolated from Floreana in their dealings, have come to understand that the island represents the future of the tourism business in the archipelago.

At the beginning of our fieldwork in 2009, we were able to confirm local uneasiness regarding the development of tourism in the island. In 2010, given the possibility that the GNP would offer new quotas for daily small boat tours, some Floreana businessmen declared to the Park's directors the de facto impossibility of locals to access these quotas. Upon our return to the island in 2011, we noticed a significant transformation in the tourism infrastructure such as new infrastructure in the docking area, arts and crafts shops, and new lodging all denoting increased local participation in tourism. A rumor circulated that a regional entrepreneur was going to build a new hotel. One of the neighbors of the intended hotel site said, "A hotel like that with multiple floors means another car, another boat, and more water consumption." Speaking more explicitly to the change of lifestyle that such a project could imply for the island, she lamented, "We will have to close the door upon leaving [our houses], something that we are not used to here."

Without a doubt, the local community desires tourist development to improve their consumption capacity and quality of life, but there are at least three factors that hinder this goal: (1) their inability to access and to secure, much less control, the flow of tourist benefits; (2) the evidence of foreign investment in Floreana with potential to further limit opportunities for local control and development of local tourism; and (3) the evident danger that some forms of tourism would negatively impact local values and a lifestyle cherished by residents, one of tranquility, security, and social cohesion. For these reasons, locals petitioned for protection from external investors and proposed a model of CBT for which the community would become the main agent. The model recognized community members as operators of daily tours and consequently the main managers of tourist flows.

In this way, Floreana is configured as a place where there is a confluence of two levels of decision-making (regional and local) in a joint initiative to transform tourism in the island into a community-based model. CBT is expected to satisfy the eco-tourism requirements of the GNP and, at the same time, the local protection and control of tourism that Floreanos explicitly demanded through their community assembly, the main local decision-making institution. This goal implies a new model of commons pools resources (CPR) management with tourism use which, as we will see, requires the crafting of new institutions.

This process may be simple in appearance but as we dig deeper into its dynamics and consequences it becomes far more complex. It requires a transformation of the system of governance of CPRs around tourist activities, which will only be possible if there is collective action at the local and regional levels. The ethnographic registry of the events is very rich, showing the different dimensions of the process, the variety of meanings they acquire, and above all their intricate and non-lineal nature. From this perspective, the institutional approach synthesized in the IAD framework (Ostrom 1990, 2011) has been useful in helping us understand the whole process, and two of its central analytical concepts rules and action situations have served as tools to organize our data.

A transformation in the governance system of a set of resources (e.g., landscape, species, history, culture) implies a change in the basic rules that regulate the appropriation and use of these CPRs. In designing a new form of tourism, Floreanos seek to confront an impinging "appropriation problem," in other words, a situation where outside resource users would benefit disproportionately from the use of local CPRs. This is likely to occur in the absence of collective action mechanisms regulating the distribution and long-term outcomes of tourism. There are rules-in-use that need to change at the regional and local levels. Following the IAD framework, we can identify rules that regulate different aspects of the appropriation of resources. The process that is sought in Floreana implies a transformation in the rulesin-use that regulate CPRs toward a set of intended rules at regional and local levels (see Table 1). The analysis of this rule-crafting process allows us to characterize the development of CBT in Floreana.

This intended transformation of the appropriation and use rules of local CPRs would clearly have a spatial effect in the flows of tourists to the island, reducing their size while at the same time opening new sites for visits. The objective is to reduce tourist visits by one third (from 23,000 to 8,000), and open de facto three sites (see Figure 1). Among these are Lobería and Cerro Allieri, which are currently not used because of the short length of the daily tours, and Post Office, which is located on the northwest coast. While it is one of the emblematic places to visit in the whole archipelago, Post Office is currently reserved exclusively for cruise ship tourism. In this way, Asilo de la Paz would not be the only place visited by land, and there would be an attractive site enabling tourists to remain for several days. This in turn would generate local demand for food and lodging services, guides, and other activities such as sailing, scuba diving, and snorkeling.

This first approximation of rule changes towards the development of CBT represented a point of departure for a series of interactions within and between local and regional levels, to which we turn our attention subsequently. To organize our data in a way that is intelligible and comparable between levels, we have used the conceptual unit called action situation (AS) (Ostrom 2011), conceived of as a context of interaction, negotiation, and creativity and composed of a complex web of multiple and recursive relations. The potential components of these action situations are open to adaptation to specific case studies. In our analysis, we delimit two different $\mathrm{AS}$, corresponding to each of the two main levels in which the process of developing CBT takes place: the regional and the local. Within these AS, we pay attention to seven fundamental components each having their respective internal dynamics: (1) the CPRs subject to use in tourist activities; (2) the actors that participate in collective action situations; (3) perceptions, knowledge, and worldviews 
Table 1. Rules Transformation

Rules In Use
Intended Rules -
Regional Level
Intended Rules Local Level

\begin{tabular}{|c|c|}
\hline \multirow[t]{2}{*}{$\begin{array}{l}\text { Boundary } \\
\text { Rules }\end{array}$} & $\begin{array}{l}\text { *Tourist activities in GNP are } \\
\text { subject to quotas that can or } \\
\text { be acquired by individuals o } \\
\text { corporations. }\end{array}$ \\
\hline & $\begin{array}{l}\text { *The local Floreana populat } \\
\text { is de facto excluded from th } \\
\text { new quotas. }\end{array}$ \\
\hline $\begin{array}{l}\text { Position } \\
\text { Rules }\end{array}$ & $\begin{array}{l}{ }^{*} \text { No consideration for local } \\
\text { community participation in } \\
\text { tourist activities }\end{array}$ \\
\hline
\end{tabular}

Scope

Rules
*Community access (as a collective) to tourist quotas: local community becomes a tourist actor

*Limits on private use of tourist CPRs
${ }^{*}$ Creation of a local (community) tourism organization

*All the members of the community would have rights to participate in the community tourist organization.

tourist within the GNP

Choice

*The quotas and regulations for tourist activities within the GNP in Floreana are decided at the regional level.

\begin{abstract}
*Delimitation of sites that can be visited and the types of ourist within the GNP
\end{abstract}

\begin{abstract}
*Opening of new sites in Floreana and exclusive concession to the community organization for their use
\end{abstract}

*Provide quotas of regulated activities (daily tours, scuba diving tours) to the community

${ }^{*}$ Reduction of the number of tourists that visit the island

*Drafting of new legislation that allows for some degree of exclusivity for community led tourist activities in Foreana
${ }^{*}$ Development of regulations and system of community led tourist by the local assembly that actors use to direct their actions towards the CPRs; (4) forms and contexts of the actions; (5) governance tools (e.g., regulations, management plans, assessment mechanisms) that they use in their actions; (6) intended rule-crafting; and (7) the expected outcomes. In this way, the AS helps organize ethnographic data and determine the tensions, contradictions, limitations, and catalysts of collective action both within each level of analysis as well as between them (see Figure 2 ). We must bear in mind that the AS in our study is focused on generating a new governance framework for the use and appropriation of CPRs.

\section{The Archipelago as an Action Situation}

At the regional level, we find eight main actors grouped in two camps according to our interpretation of their worldviews. The first set is comprised of the Environment Ministry, the
GNP, and a group of NGOs (especially the World Wildlife Fund and the Charles Darwin Foundation) that habitually work with the GNP in financing different activities and providing technical support for the Park's conservation policies. This set shares a similar worldview from which the archipelago is understood as an integrated whole subject to environmental protection. While the human population is increasingly taken into account as an active agent in the socioecological system, there is still a lingering perception of them as the environmental problem. For this set of actors, the tourist model in the Galápagos, despite being the financial base for conservation, follows a problematic course that endangers the socioecological system. From this position, an improvement in the quality of life of the population from the archipelago serves as a means for environmental conservation, but not an end in itself. We call this worldview "environment first." 
A second set of actors at this level is composed of the Tourism Ministry, the council of the Galápagos Government, regional authorities, and the local government of Floreana. This group shares a vision of Galápagos based on local populations and the perspective of socioeconomic development, which we call "humans first." Despite its increasing adoption of an environmental sensibility, these actors hold that the improvement in the conditions of local inhabitants is an end in itself, and that tourism is the means to achieve it.

Over the course of our research, we participated in multiple meetings and gatherings of these two groups of actors to discuss the issue of Floreana and its future. On several occasions, these have been supported by the GNP and on others by the Tourism Ministry, which has sought to put special emphasis on the possibilities and benefits of CBT as it has been developed in state-level policy. From a communicative point of view, all of these meetings have been marked by an administrative, highly formal tone. Notwithstanding this bureaucratic veneer, in many cases the political and electoral interests that motivate these actors became evident. In general, the framework and the forms of action in this AS are highly marked by the problems of inter-institutional governance and mistrust in the archipelago. Nonetheless, the strong leadership of the GNP and some NGOs are evident at all times in this process of collective action.

Notably absent in the group of participants at this level are regional tourism entrepreneurs, who are formally excluded from meetings discussing the transformation of appropriation and use of CPRs in Floreana. These entrepreneurs would see a reduction in their present and future business opportunities on the island if the proposed set of rules for CBT is implemented as outlined above. Their worldview is quite distinct from the two other groups described here; for them, the islands are seen through the logic of the market enabling them to secure benefits through the development of tourism. Their forms of governance (market-based competition) and desired outcomes distinguish them from the rest of the actors in this AS. Their lack of formal participation does not, however, mean that they are unable to act upon the process, even if indirectly or implicitly. This is very evident for Floreana locals, who do not hesitate in expressing, as one informant stated, that "what some people are afraid of is that if we organize and begin to function collectively, we are an example, if not a threat, to the other ways of doing tourism here."

At the level of this AS, governance over the CPRs is based mainly on formal rules. The tools that the various actors propose for effecting an eventual transformation in the rules that govern the island's CPR, include legislation and legal sanctions, new projects, and management plans aimed at setting the scope of CBT in Floreana within the regional context of the GNP. The intended rules shown in Table 1 seek in general terms to make the community the central actor of tourism in the island, to limit the presence of external private initiatives, and to open new visiting spaces within the park's territory in Floreana. The main expected outcomes would be a new set of regulations guiding tourism and environmental conservation.

\section{The Island of Floreana as Action Situation}

At the local level, CPRs are defined in more specific terms and new actors appear: the canton government, the community assembly, local groups (e.g., kinship, the agriculture association), the general population, and local tourism entrepreneurs. The GNP and NGOs also participate at this level. Thus, we have three actors repeated at both levels (GNP, NGOs, and local government); they are the protagonists of the process. The worldview that we labeled "environment first" is constrained at the local level and reveals itself as tangential, in spite of the presence of the GNP and conservation NGOs. The hegemonic worldview at the local level is what we call "humans first." The market vision is explicitly present given that local tourism entrepreneurs have a central role in the process. At this level, then, we find an arguably more complex landscape of different worldviews.

It is also important to take into account that in this AS, the forms and contexts of communication to generate collective action assume a very different nature from the administrative, highly formal, and technical tone of the regional AS. The assemblies and face-to-face relationships in the community are the main arenas of interaction in which the leadership of the elected local government's president is crucial. The forms and contexts of collective action are therefore mainly informal, something unusual for the GNP and NGO officials who nevertheless also have a protagonist role at the local level. Officials exert a significant level of control over strategic resources necessary for the process of implementing CBT in Floreana. They firmly support the development of a solid CBT as they think that this strategy could help to regulate and control tourist flows. In this local action situation, formal governance (local regulations for instance) also has a marked presence, but it is mediated by community norms regarding reciprocity, trust, equity, and commitment.

The local action situation intends to promote rule crafting (see Table 1) with the explicit objective of opening tourist activities to the local population (boundary and scope rules) and the development of a community organization to govern the use of the tourism-related CPRs (choice rules). In this sense, the process to generate rules at this level can be considered more complex than that found at the regional level. Their implementation at the regional level does require the acquiescence of higher levels of state administration that authorize this exceptionality for Floreana; it also needs to avoid the pressure coming from the business sector (boundary rules), but at the local level it requires the development of an entirely new community tourism organization (position rules) and consistent commitment from families and individuals.

Floreanos are quite clear in private (interviews) and public statements (assemblies) that they do not want the current tourism model, but they differ in their preferred alternatives and the means to procure them. This internal heterogeneity, even in such a small locality, cannot be ignored, as it underscores the level of trust necessary to implement a CBT program. In the face of external actors GNP and NGOs such 
as in meetings and general gatherings, the community presents itself as much more cohesive than what it later shows in internal meetings. The CBT initiative, proposed originally by some local entrepreneurs, invites mistrust among those who think the process is nothing more but a stratagem of some to advance their personal interests. While they are also members of the community, local entrepreneurs have their own worldview based on governance tools guided by competition rather than equity or reciprocity. They also have their own intended outcomes (e.g., an increase in economic benefits from tourism) that only partially coincide with the outcomes expected at the local level, such as tourism regulation, maintenance of tranquility and safety, local development, and the establishment of a community organization for tourism-related activities.

To the majority of the community, tourism is understood as a means to an end, as stated publicly by one of its members:

[Tourism is] an engine that needs to strengthen fishing, agriculture, craftsmanship. Everything rotates around the motor. But tourism should not change our lives so that we buy everything in Santa Cruz. We need to take into account that not all of us will be in tourism; fishing and agriculture are necessary. We need to strengthen those other sectors besides tourism.

Local tourism entrepreneurs move in an ambivalent position in which they strongly support community control of tourist activities, while at the same time they are afraid that community control may endanger their private activities. Consequently, their basic objective is to clearly untangle the collective and private parts of tourist activities, and it is here that mistrust emerges. Overcoming this constraint is key to the process at the local level and where we have found the main tensions and contradictions.

The local government, with the leadership of its president (a member of a family dedicated to tourism), seeks the integration of the entire community and to promote development beyond tourism. In November 2011, a document was drafted to form a "Pre-association for development and tourism in Floreana" as the nucleus of the future local tourism organization. In preparatory meetings, it was decided that the pre-association should include a representative from each of the island's families, regardless of their direct link to the tourism business. The document attempted to synthesize all the sensibilities of community members and in doing so, it sought consensus. First, it included a general proposal (developed in a previous workshop) for a CBT organization pursuing the following goals: articulation of private and community interests, community management of tourist flows, and direct community control in some strategic activities (e.g., transport) combined with substantial opportunities for private sector initiatives (e.g., lodging, restaurants). Secondly, the document posited a definition of tourist development not as a strategy in itself but as a means towards more general development for the community. This included the promotion of agricultural development (of much interest to a significant part of the population) and directing resources generated in tourist activities to finance other aspects of community life (e.g., professional training, education). Finally, there were commitments by the community for a more eco-friendly management of their lifestyle in the island. This explicitly supposed planning of the urban area, energy, and resource sectors to conform to the objectives of sustainability that are expected in the archipelago. In this way, the predicted costs and benefits of the process were defined. With all of this, what was intended was to gain a consistent degree of commitment within the community, as well as to pressure higher levels of government to prevent the arrival of external investors in the tourism sector, a common objective of the local population.

The document was presented and discussed collectively and explained to different individuals and groups informally by the members of the local government; the objective was to gain the signatures from all the families in the community. We participated in the entire process and witnessed the concerns and doubts of some, as well as the strong support of others. In this way, we were able to consistently evaluate the advantages and disadvantages of CBT as perceived by Floreana's population. The document was not signed by a majority of community members as intended because some people maintained doubts about the real beneficiaries of an initiative of this type. Local people not involved in tourist activities consider that the CBT initiative could benefit mostly local tourism entrepreneurs, increasing their income instead of ensuring community access to this activity. This fact creates tension around the potential effect of the CBT: would it sustain community cohesion or increase internal differentiation? Obviously, that will depend on the way that CBT is organized, but in any case, it reflects a lack of trust within the local community. As a counterpoint, however, all the members of the local government, which represents the different local interests, did sign it.

From that time, the process of developing CBT in Floreana has continued to advance despite the challenges. In 2012, evaluation reports required to open new spaces for tourism in the GNP have been drafted, several workshops were organized to set ecological guidelines in the construction and use of resources, and a consultant was hired to design the community tourism organization. In addition, the GNP has continued to consistently support the process, and state agencies seem willing to grant exclusivity to the community organization in the management of tourism-related activities on the island. Within the community, however, there still persist doubts and mistrust, which give the local AS a more complex and uncertain dynamic than what could be supposed from the outside and without an ethnographic consideration of the process.

\section{Within Level and Cross-Level Challenges for CBT Development}

In Floreana, and probably in most protected areas where CBT projects are proposed, it is necessary to consider the 
multi-level nature of the process of transforming the use and appropriation of CPRs by tourist activities, since these are subject to different regimes of property use and control. In addition, in this case both levels of action (regional and local) maintain a particular configuration where, despite a hierarchical relationship, there is a significant level of mutual dependence: both levels are needed to achieve their objectives. The development of CBT would be impossible from the regional or local levels operating independently. This multilevel alignment is not surprising given that the process (CBT development) emerged as a proposal from different sectors, at both levels, which are dissatisfied with the current tourism model. The intended rules themselves (see Table 1) do not reveal incompatibilities between levels but rather complementarity and overlap. On the other hand, the multi-level institutional framework, which is being configured around CBT in Floreana, seems a priori to be compatible with the design principles that characterize robust institutions for CPR management (Cox, Arnold, and Villamayor Tomás 2010; Ostrom 1990). In particular, the process has aimed at defining boundaries clearly, to develop congruence between appropriation and provisioning rules and local conditions, to recognize the rights of participants and affected parts to self-organize and craft rules, and to propose a system organized as a nested enterprise. It is not clear, however, how monitoring, sanctions, and mechanisms for conflict resolution will be developed and implemented. Is this then a process that, despite seeking a marked change in the use of CPRs, will be unproblematic? Dividing collective action into different signifying components and articulating them into two action situations at distinct levels helped us to better understand the process of development of the CBT in Floreana, including highlighting tensions and contradictions within and between levels.

The process of developing CBT in Floreana points to three discussion points which could be common to other cases. The first is the importance of local participation and the role of higher-level actors in excluding other actors from the process. While the exclusion of regional and national entrepreneurs could represent a roadblock for the process, the full inclusion of Floreana's entrepreneurs, in spite of local tensions, is helping to legitimize the process of implementing a new model of tourism. The second is the importance of considering worldviews and the intended outcomes in the internal dynamics of each action situation as well as the articulation between them. Finally, our analysis highlights the importance of coherence in crafting rules (at different levels and for different types of rules) defining control and regulation of CBT development and of tourism operations. The analysis of the case of Floreana shows us a situation with all these tensions (Figure 2) between the different components of each AS as well as between both AS.

\section{Within-Level Challenges}

At the regional level, we see two fundamental problems. On the one hand, there is a tension between worldviews and intended goals. The apparent coherence of the process establishing governance tools, rules crafting, and outcomes contrasts with the divergent knowledge that divide the main actors participating in the AS into two groups. This is an important factor for understanding the internal dynamic of this AS, since it ultimately means a larger compromise for a group aiming primarily at environmental conservation. On the other hand, the formal exclusion of regional and national entrepreneurs from the AS (represented in Figure 2 with black boxes and a separation line) implies a weakening of the AS itself, motivating this group to form a lobby that we know has pressured and will continue to do so at the state level to block the process of rule-crafting and consequently undermine the intended outcomes (which undoubtedly go against their interests).

At the local level, the tensions and contradictions increase as the local entrepreneurs are included in the AS. It is also evident that there is a need for a plural integration of multiple stakeholders in the CBT model at the local level, despite the fact that it may increase complexity because of the heterogeneity of worldviews, proposed governance tools, and expected outcomes. The tensions are multiplied, but they can be solved only in their emergence and through an adaptive process. This ethnographic case has demonstrated that Floreanos analyze the costs and benefits of this process beyond their economic dimension and clearly shows that even such a small community is not a homogeneous entity. The results indicate that one of the central aspects of the development of CBT is located at the community level. Thus, integrating individual and collective interests must have the central role in the collective action process required to change tourism from business-as-usual to CBT model of tourism.

\section{Cross-Level Challenges}

The two AS do not reflect only two different levels of collective action and institutional interplay, they also exhibit different sociocultural contexts. While differences in worldviews are common to both levels, it is also obvious that each level has different expectations of outcomes, that is, CBT as means to environmental conservation or to economic development. While there has been some coordination between levels towards the development of CBT, reconciling these differences will require more attention to the development of monitoring, sanctions, and conflict resolution mechanisms. Regarding the development of CBT in Floreana, the central actors are sufficiently represented in both AS (GNP, NGOs, and local government). At the local level, participation and collective decision-making is direct, occurring through assemblies. The problems of different worldviews are not as significant as those that habitually occur between scientific and indigenous knowledge (Natcher, Davis, and Hickey 2005). In this case, it is a question of differing perspectives within the same cultural context. Consequently, applying Young's (2006) terminology, the multilevel analysis in Floreana is similar to a "negotiated agreement," with the possibility that 
Figure 2. Regional and Local Action Situations. Each action situations (AS) (regional and local) is composed of seven elements that are represented in columns formed by boxes, from left to right: (1) the main CPRs subject to use in tourist activities; (2) the actors that participate in collective action situations (in grey the protagonists of the process); (3) worldviews (perceptions, knowledge) that the actors use to direct their actions towards CPRs; (4) forms and contexts of actions; (5) the governance tools that actors use in their actions (e.g., regulations, management plan, assessment mechanisms); (6) the rule-crafting intended; and (7) the expected outcomes (separated in boxes). Boxes are articulated from left to right, so that the actors are linked to resources and, in turn, are grouped around worldviews, continuing the different elements of the process towards outcomes. Although this is not a linear process, it acquires this appearance for illustrative/graphic purposes. At the end of each AS, arrows link outcomes and resources indicating that the outcomes end up affecting the use and management of resources. At the regional AS, the actor "tourism entrepreneurs" (dark box at the bottom) is formally outside the AS and appears separate from the set by a line. However, an arrow connected to outcomes contemplates its de facto influence on the process. In the case of the local AS, the local tourism entrepreneurs are entirely integrated to the process. Through the lines we show the main tensions of the process, both within each AS (for example between worldviews) as also between the components of the two AS (for example, between forms and contexts of the actions, the governance tools, and even the outcomes within or between levels).

Regional Action Situation

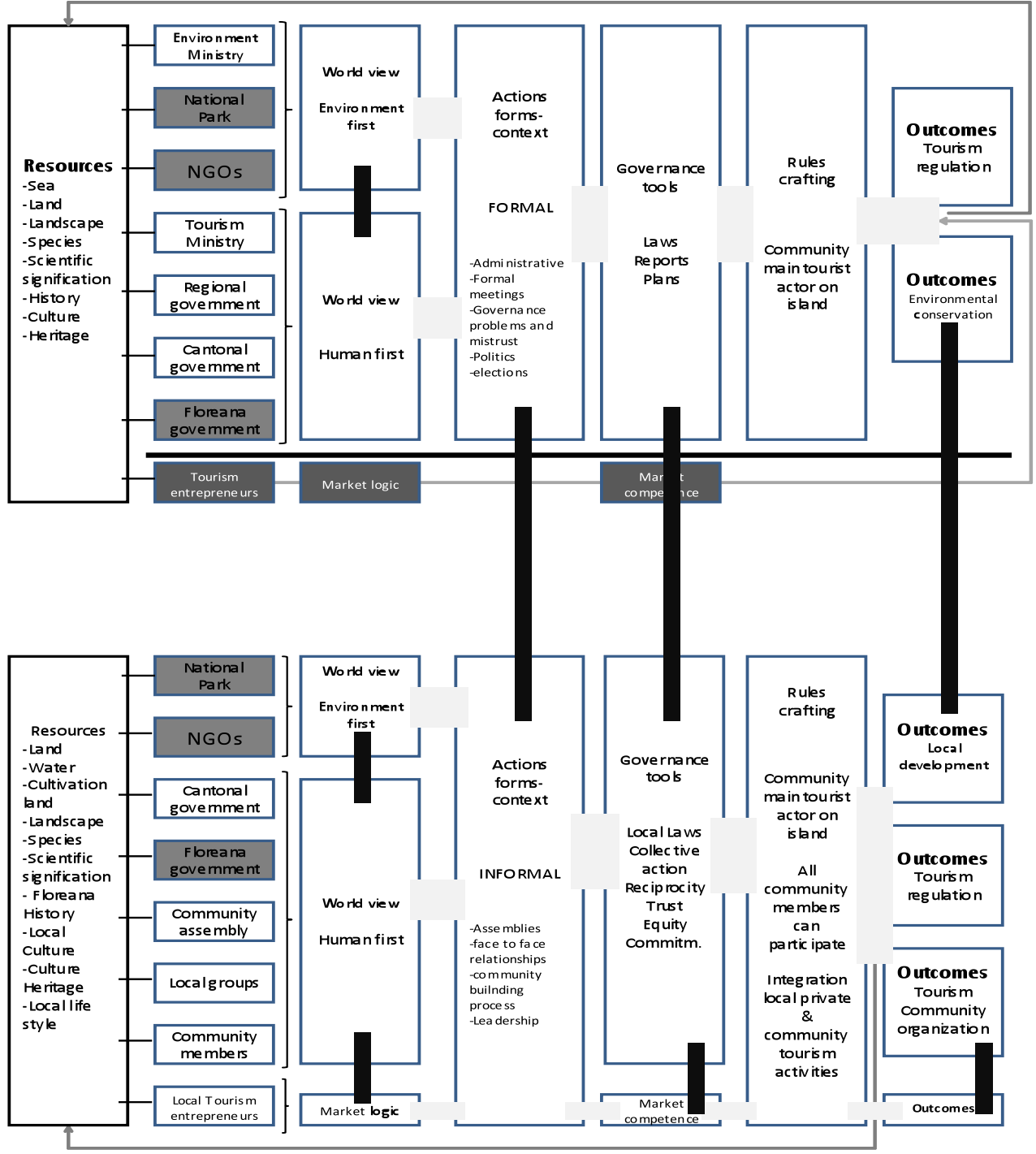

Lo cal Action Situation 
it will evolve into a co-management system with strong governance mechanisms at the local level (Berkes 2002). There are inherent tensions that occur in all processes of changing resource management (Carlsson and Berkes 2005; Cash et al. 2006). As we see in the description of the AS, the regional actors are varied and do not share a unified perspective of "the regional." The community, for its part, is perhaps even more complex and heterogeneous. Nonetheless, as these two levels maintain a clear relationship of interdependence, it is worthwhile considering them as "adjacent action situations" (McGinnis 2011b); in other words, as "outcomes generated in one action situation help determine the rules under which interactions occur within the other action situation" (McGinnis 2011b:52). Even if we consider other levels (such as the state or market), both form a coalition against national and regional entrepreneurs on one hand, and, on the other, both seek to pressure the state in the concessions necessary for the development on CBT on the island.

Nonetheless, once the process of transforming a multilevel management regime has begun as in Floreana it is likely to be subjected to non-linear trends according to its inherent complexity. The development of the process will be determined by events, agency, and contingencies more than by a priori rules or arguments, which can lead to different trajectories from specific events that create uncertainty. An example is the importance that particular leaders have in the two action situations studied. The personalities and visions of the park director, the local government president, or NGOs representatives strongly influence together with structural aspects the dynamic of crafting a plan for CBT. Any change among these actors at particular stages of the process is also likely to influence the outcome.

The complex nature of multi-level governance of CPRs implies that diverse worldviews and different forms of interpersonal relationships (contexts and forms) are important components of collective action processes. They influence the negotiation of trade-offs needed to balance differences in expected outcomes (e.g., reconciling environmental conservation and local development). CBT is intended to promote management that takes into account that different resources associated with tourism are held not only under different ownership systems but also under different perspectives of management and use.

\section{Conclusions}

This case study sheds light on a number of theoretical and practical premises. On the one hand, it demonstrates the utility of combining institutional analysis (the IAD framework) with an ethnographic methodology. This strategy allows us to study the transformation of a CPR governance system as a process involving different levels of analysis and, at the same time, the internal dynamics of each of them. Ethnography confronts the complexity of study settings and cautions against the danger of schematic and mechanic simplification that an analytical model could impose in the absence of a real-world application. Confronting formalism and abstraction, ethnography not only brings us closer to the multiple dimensions of the process analyzed here but also the internal heterogeneity of its components even in a very small community such as Floreana. The IAD, on the other hand, offers a flexible analytical tool and a rich terminology that helps the systematization and comparative aspects of a case study (Ostrom 2011; Poteete, Jansen, and Ostrom 2010).

Departing from this position and taking into account the complexity and inherent multilevel nature of the processes of CBT development, the IAD framework helped us to organize ethnographic data to facilitate within- and between-level analysis. We hope that the case study presented here helps to shed light on the complexity of developing rules and institutional arrangements for tourism activities in protected areas.

\section{References Cited}

Acheson, James M.

2006 Institutional Failure in Resource Management. Annual Review of Anthropology 35 :117-134.

2011 Ostrom for Anthropologists. International Journal of the Commons 5 (2):319-339.

Andrada, Javier, Pedro Cantero, and Esteban Ruiz-Ballesteros

2010 Habitar Galápagos: Encrucijada de Naturaleza y Cultura. Quito, Ecuador: Presidencia de la República del Ecuador, Universidad de Cuenca.

Berkes, Fikret

2002 Cross-Scale Institutional Linkages: Perspectives from the Bottom Up. In The Drama of the Commons. Elinor Ostrom, Thomas Diez, Nives Dolsak, Paul C. Stern, Susan Stonich, and Elke U. Weber, eds. Pp. 293-321. Washington, D.C.: National Academy Press.

Briassoulis, Helen

2002 Sustainable Tourism and the Question of the Commons. Annals of Tourism Research 29(4):1065-1085

Brondizio, Eduardo S., Elinor Ostrom, and Oran R. Young 2009 Connectivity and the Governance of Multilevel SocialEcological Systems: The Role of Social Capital. Annual Review of Environmental Resources 34:253-278.

Carlsson, Lars, and Fikret Berkes

2005 Comanagement: Concepts and Methodological Implications. Journal of Environmental Management 75(1):65-76.

Cash, David W., W. Neil Adger, Fikret Berkes, Po Garden, Louis Lebel, Per Olsson, Lowell Pritchard, and Oran Young

2006 Scale and Cross-Scale Dynamics: Governance and Information in a Multilevel World. Ecology and Society 11(2):8.

Consejo de Gobierno de Galápagos (INEC)

2009 Encuesta de Condiciones de Vida. Puerto Ayora, Ecuador: Consejo de Gobierno de Galápagos.

2011 Censo población Ecuador. Quito, Ecuador: Consejo de Gobierno de Galápagos.

Cox, Michael, Gwen Arnold, and Sergio Villamayor Tomás 2010 A Review of Design Principles for Community-Based Natural Resource Management. Ecology and Society 15(4):38. 
Gardener, Mark, R. Rachel Atkinson, and Jorge Luis L. Rentería 2010 Eradications and People: Lessons from the Plant Eradication Program in Galápagos. Restoration Ecology 18(1):20-29.

Gonzalez, José, Carlos Montes, José Rodriguez, and Washington Tapia 2008 Rethinking the Galápagos Islands as a Complex System: Implications for Conservation and Management. Ecology and Society $13(2): 13$.

Grenier, Christophe

2007 Conservación contra natura. Las islas Galápagos. Quito, Ecuador: Abya-Yala

Healy, Robert G.

2006 The Commons Problem and Canada's Niagara Falls. Annals of Tourism Research 33(2):525-544.

Hiwasaki, Lisa

2006 Community-Based Tourism: A Pathway to Sustainability for Japan's Protected Areas. Society and Natural Resources 19(8):675-692.

Holden, Andrew

2005 Achieving a Sustainable Relationship between Common Pool Resources and Tourism: The Role of Environmental Ethics. Journal of Sustainable Tourism 13(4):339-352.

Kruger, Oliver

2005 The Role of Ecotourism in Conservation: Panacea or Pandora's Box? Biodiversity and Conservation 14(3):579-600.

Li, WenJun

2006 Community Decision Making, Participation in Development. Annals of Tourism Research 33(1):132-143.

McGinnis, Michael D.

2011a An Introduction to IAD and the Language of the Ostrom Workshop: A Simple Guide to a Complex Framework. Policy Studies Journal 39(1):169-183.

2011b Networks of Adjacent Action Situations in Polycentric Governance. Policy Studies Journal 39(1):51-78.

Moore, Susan A., and Kate Rodger

2010 Wildlife Tourism as a Common Pool Resource Issue: Enabling Conditions for Sustainability Governance. Journal of Sustainable Tourism 18(7):831-844.

Natcher, David C., Susan Davis, and Clifford G. Hickey

2005 Co-Management: Managing Relationships, Not Resources. Human Organization 64(3):240-250.

Neves-Graça, Katja

2004 Revisiting the Tragedy of the Commons: Ecological Dilemmas of Whale Watching in the Azores. Human Organization 63(3):289-300.

Okazaki, Etsuko

2008 A Community-Based Tourism Model: Its Conception and Use. Journal of Sustainable Tourism 16(5):511-529.

Ostrom, Elinor

1990 Governing the Commons. The Evolution of Institutions for Collective Action. Cambridge, United Kingdom: Cambridge University Press.

2005 Understanding Institutional Diversity. Princeton, N.J.: Princeton University Press.

2011 Background on the Institutional Analysis and Development Framework. The Policy Studies Journal 39(1):7-27.
Ostrom, Elinor, Roy Gardner, and James Walker

1994 Rules, Games, and Common-Pool Resources. Ann Arbor: The University of Michigan Press.

Parque Nacional Galápagos (GNP)

2012 Parque Nacional Galápagos. URL: $<$ http://www. galapagospark.org> (accessed July 30, 2012).

Poteete, Amy R., Marco Jansen, and Elinor Ostrom

2010 Working Together: Collective Action, the Commons, and Multiple Methods in Practice. Princeton, N.J.: Princeton University Press.

Roberts, Sherma, and John Tribe

2008 Sustainability Indicators for Small Tourism Enterprises An Exploratory Perspective. Journal of Sustainable Tourism 16(5):575-594.

Ruiz-Ballesteros, Esteban

2011 Socio-Ecological Resilience and Community-Based Tourism. An Approach From Agua Blanca, Ecuador. Tourism Management 32(3):655-666.

Ruiz-Ballesteros, Esteban, and Macarena Hernández-Ramírez

2010 Tourism That Empowers? Commodification and Appropriation in Ecuador's Turismo Comunitario. Critique of Anthropology 30(2):201-229.

Sick, Deborah

2008 Social Contexts and Consequences of Institutional Change in Common-Pool Resource Management. Society and Natural Resources 21(2):94-105.

Stem, Caroline, James P. Lassoie, David R. Lee, David D. Deshler, and John W. Schelhas

2003 Community Participation in Ecotourism Benefits: The Links to Conservation Practices. Society and Natural Resources 16(5):387-413.

Stronza, Amanda

2010 Common Management and Ecotourism. Ethnographic Evidence from the Amazon. International Journal of the Commons 4(1):56-77.

Tao, Teresa, and Geoffrey Wall

2009 Tourism as a Sustainable Livelihood Strategy. Tourism Management 30(1):90-98.

Taylor, Peter Leigh, and Antony S. Cheng

2012 Environmental Governance as Embedded Process: Managing Change in Two Community-Based Forestry Organizations. Human Organization 71(1):110-122.

Theodori, Gene

2005 Community and Community Development in ResourceBased Areas: Operational Definitions Rooted in an Interactional Perspective. Society and Natural Resources 18(7):661-669.

Tosun, Carl, and Dallen J. Timothy

2003 Arguments for Community Participation in Tourism Development. Journal of Tourism Studies 14(2):2-11.

Wagner, John, and Malia Talakai

2007 Customs, Commons, Property, and Ecology: Case Studies from Oceania. Human Organization 66(1):1-10. 
Watson, James, Mandy Trueman, Marta Tufet, Scott Henderson, and Rachel Atkinson

2010 Mapping Terrestrial Anthropogenic Change across the Galápagos Archipelago. Oryx 44 (1): 79-82.

West, Paige, James Igoe, and Dan Brockington 2006 Parks and Peoples: The Social Impact of Protected Areas. Annual Review of Anthropology 35(1):251-277.

World Tourism Organization (WTO)

2006 Poverty Alleviation through Tourism. A Compilation of Good Practices. Madrid, Spain: World Tourism Organization.

World Wide Fund for Nature

2001 Directrices para el desarrollo del turismo comunitario. Gland, Switzerland: World Wide Fund for Nature.
Wunder, Sven

2000 Ecotourism and Economic Incentives An Empirical Approach. Ecological Economics 32(3):465-479.

Yin, Robert

2009 Case Study Research, Design, and Methods. Thousand Oaks, Calif.: Sage.

Young, Oran

2006 Vertical Interplay among Scale-Dependent Environmental and Resource Regimes. Ecology and Society 11(1):27. 